\title{
Comparison of Pharmacokinetic and Pharmacodynamic Effects of Two Hydrofluoroalkane Formulations of Salmeterol
}

\author{
Morde $\mathbf{N}^{1}$, Rebello $\mathrm{J}^{1}$, Brashier $\mathrm{B}^{1}$, Garg $\mathbf{M}^{2 *}$, Naidu $\mathbf{R}^{2}$, Birhade $\mathrm{A}^{2}$, lyer $\mathrm{K}^{2}$ and Jadhav $\mathbf{R}^{2}$ \\ ${ }^{1}$ Cipla Ltd., Peninsula Business Park, Lower Parel, Mumbai 400013, India \\ ${ }^{2}$ Sitec Labs Pvt. Ltd., PEE-DEE Info Tech, Mahape, Navi Mumbai 400710, India
}

\begin{abstract}
Introduction: To compare the Pharmacokinetic (PK) and Pharmacodynamic (PD) effects of two Hydrofluoroalkane (HFA) formulations of salmeterol xinafoate (Test HFA formulation, Cipla Ltd., India; Reference HFA formulation, Allen and Hanburys, UK) administered using pressurized metered dose inhalers.

Methods: Three separate randomized, crossover, PK studies and one PD study comparing the efficacy and safety of the two HFA formulations of salmeterol xinafoate $(25 \mu \mathrm{g}$ per actuation) in healthy subjects were conducted. The PK assessments of the two formulations were done without charcoal blockade, with charcoal blockade, and with a Volumatic spacer device using a single dose. A PD study was also conducted to evaluate the systemic exposure of the two formulations using three different doses $(50 \mu \mathrm{g}, 150 \mu \mathrm{g}$ and $300 \mu \mathrm{g})$.

Results: In the PK study without charcoal, the $90 \% \mathrm{Cl}$ for the difference between the two formulations for $\mathrm{AUC}_{0.1}$ was within the bioequivalence limits of $80-125 \%$; however, $C_{\max }$ marginally exceeded the upper bioequivalence limit to $136 \%$. In the PK study with charcoal, the $90 \% \mathrm{Cl}$ for the difference between the two formulations for $\mathrm{C}$ was within the bioequivalence limits of $80-125 \%$; however, $A \cup C_{0-t}$ marginally exceeded the upper bioequivalence limit to $128 \%$. The impact of marginally higher systemic exposure was therefore further evaluated in the PD study. The PD study confirmed there were no greater systemic safety effects of the test formulation on the primary PD endpoints such as heart rate and serum potassium as well as on other safety PD endpoints such as blood glucose and QTc interval. The PK study with spacer demonstrated bioequivalence between the test and reference formulations. Both formulations were safe and well tolerated.
\end{abstract}

Conclusion: The test HFA formulation of salmeterol was therapeutically equivalent to the reference HFA formulation of salmeterol when used with and without a spacer.

Keywords: Pharmacokinetics; Salmeterol; Metered dose inhalers

Abbreviations: AE: Adverse Event; $\mathrm{AUC}_{0-\mathrm{t}}$ : Area Under the Plasma Concentration Versus Time Curve from Time 0 to Time $t$; $\mathrm{AUC}_{0-30}$ min: AUC During First $30 \mathrm{~min}$ after Inhalation; $\mathrm{AUC}_{0 \text {-inf }}$ : Area Under the Plasma Concentration Versus Time Curve from Time 0 Extrapolated to Infinity; BMI: Body Mass Index; CFC: Chlorofluorocarbon; $\mathrm{C}_{\max }$ : Maximum Plasma Concentration; CI: Confidence Interval; $\mathrm{CV}$ : Coefficient of Variation; cm: Centimeter; ECGs: Electrocardiograms; z: Greater Than or Equal to; GCP: Good Clinical Practice; HFA: Hydrofluoroalkane; h(s): Hour(s); Ke: Elimination Rate Constant; kg (s): Kilogram(s); $\leq$ : Less Than or Equal to; LSM: Least Square Mean; L/min: Liters/Minute; $\min (\mathrm{s})$ : Minute(s); mm: Millimeter; m: Meter; mL: Milli Liter; mM: Millimol; pMDI: Pressurized Metered Dose Inhaler; \%: Percent; PD: Pharmacodynamics; PK: Pharmacokinetic; rpm: Rotations Per Minute; SAE: Serious Adverse Event; SAS: Statistical Analysis Software; SD: Standard Deviation; $\mathrm{T}_{\max }$ : Time to Reach $\mathrm{C}_{\max }$; t1/2: Elimination Half-life

\section{Introduction}

According to the World Health Organization (WHO), 235 million people suffer from asthma and 65 million people suffer from moderate to severe Chronic Obstructive Pulmonary Disease (COPD) [1,2]. In 2009, 3388 people died of asthma; the age-adjusted death rate was 1.1 per 100,000 people [3]. More than 3 million people died of COPD in 2005 , which corresponds to $5 \%$ of all deaths globally. Asthma costs the European economy approximately 17.7 billion Euros while COPD accounts for 38.6 billion Euros every year [4].
Bronchodilators are prescribed either on as-needed basis or on regular basis to prevent or reduce symptoms of asthma and COPD. Longacting inhaled $\beta 2$-agonists such as salmeterol are convenient and more effective in producing maintained symptom relief than short-acting $\beta 2$-agonists [5,6]. Salmeterol significantly improves Forced Expiratory Volume in $1 \mathrm{~s}\left(\mathrm{FEV}_{1}\right)$ and lung volumes, dyspnea, health related quality of life, and exacerbation rate; and reduces the rate of hospitalization when used in combination with a corticosteroid [7-12].

The reference Hydrofluoroalkane (HFA) formulation, Serevent Evohaler (Allen and Hanburys, United Kingdom) contains salmeterol xinafoate. Cipla Limited, India has developed an alternative formulation of salmeterol xinafoate (test HFA formulation) as a cost-effective alternative for treatment of asthma and COPD. Both formulations are administered using Pressurized Metered Dose Inhalers (pMDIs).

A vital element of a therapeutic equivalence study using a clinical endpoint is demonstration of dose-response relationship, in order to

*Corresponding author: Garg M, MD, Pharmacology, Principal Investigator Sitec Labs. Pvt. Ltd., PEE-DEE Info Tech, Plot No. Gen-40, TTC MIDC, Mahape, Navi Mumbai-400710, India, Tel: +91 9833913773, +91 222778 6200/358; Fax: +9122 2778 6241; E-mail: muneesh.garg@siteclabs.com

Received April 10, 2017; Accepted April 17, 2017; Published May 02, 2017

Citation: Morde N, Rebello J, Brashier B, Garg M, Naidu R, et al. (2017) Comparison of Pharmacokinetic and Pharmacodynamic Effects of Two Hydrofluoroalkane Formulations of Salmeterol. J Bioequiv Availab 9: 405-411. doi: 10.4172/jbb.1000332

Copyright: @ 2017 Morde N, et al. This is an open-access article distributed under the terms of the Creative Commons Attribution License, which permits unrestricted use, distribution, and reproduction in any medium, provided the original author and source are credited. 
Citation: Morde N, Rebello J, Brashier B, Garg M, Naidu R, et al. (2017) Comparison of Pharmacokinetic and Pharmacodynamic Effects of Two Hydrofluoroalkane Formulations of Salmeterol. J Bioequiv Availab 9: 405-411. doi: 10.4172/jbb.1000332

confirm that a lack of difference in the clinical endpoint is truly because test and reference formulations generate a similar level of effect, and not because the study lacks sensitivity in detecting differences [13]. For salmeterol, the dose-response relationship is flat when assessment is done using either bronchodilation or bronchospasm models [14-17]. Hence, though different doses of salmeterol show marked differences in Area under the Concentration-Time Curve (AUC) and maximum plasma concentration $\left(\mathrm{C}_{\max }\right)$ in a Pharmacokinetic $(\mathrm{PK})$ study, there is no significant difference observed in an efficacy study. PK studies are therefore the most sensitive in vivo studies which provide information about the total amount of drug deposited in the lungs, pulmonary residence time, and systemic exposure; and are able to detect differences between two formulations $[18,19]$.

There is limited published data describing the extent of first pass metabolism of inhaled salmeterol [20,21]. The differences between salmeterol given with and without charcoal blockade suggest that $28 \%$ to $36 \%$ of the systemic response to salmeterol administered from an MDI is due to drug absorbed from the gastrointestinal tract. This indicates salmeterol is subjected to only partial first pass metabolism and the swallowed fraction contributes to $28 \%$ to $36 \%$ of the total systemic bioavailability [22]. Therefore, for salmeterol, area under the plasma concentration curve from administration to last observed concentration at time $t\left(\mathrm{AUC}_{0 . \mathrm{t}}\right)$ represents bioavailability from both the lung and swallowed fractions of the drug but in the presence of oral charcoal it reflects absorption from the lung only. The absorption of salmeterol in the lung is very quick $\left(\mathrm{T}_{\max } \leq 5 \mathrm{~min}\right.$ ); therefore, $\mathrm{C}_{\max }$ reflects early bioavailability from the lung, as it excludes the later component of gut bioavailability from the swallowed fraction [23]. Significant differences in pharmacodynamic (PD) systemic effects (changes in heart rate, blood glucose and serum potassium) are seen between $150 \mu \mathrm{g}$ and $300 \mu \mathrm{g}$ and between $100 \mu \mathrm{g}$ and $400 \mu \mathrm{g}$ of salmeterol [20,22].

This review discusses 3 PK studies and 1 pharmacodynamic safety that were conducted to evaluate equivalence between two formulations of salmeterol.

\section{Materials and Methods}

\section{Study design and subjects}

All the four studies were conducted according to the declaration of Helsinki, International Conference on Harmonisation of Good Clinical Practice guidelines, European guideline, and relevant national laws and regulations. All subjects provided written informed consent for participation in the studies [24-26].

The PK studies were open-label, randomized, two-treatment, twoperiod, two-sequence, single-dose, crossover, phase 1 comparable bioavailability studies in healthy volunteers under fasting conditions. The pulmonary deposition of salmeterol was assessed, by administering activated charcoal to block the gut absorption, in 24 healthy volunteers following administration of a single dose of $200 \mu \mathrm{g}(8 \times 25 \mu \mathrm{g} / \mathrm{puff})$ of test and reference HFA formulation of salmeterol (PK study with charcoal). The systemic exposure of salmeterol was assessed in 24 healthy volunteers following administration of a single dose of $200 \mu \mathrm{g}$ $(8 \times 25 \mu \mathrm{g} /$ puff $)$ of test and reference HFA formulation of salmeterol (PK study without charcoal). The systemic exposure to salmeterol with a Volumatic spacer was assessed in 24 healthy volunteers following administration of a single dose of $100 \mu \mathrm{g}(4 \times 25 \mu \mathrm{g} /$ actuation $)$ of the test and reference formulations of salmeterol (PK study with spacer). A safety PD dose-response study was conducted to evaluate the potential impact of higher PK levels on pharmacological effects in 21 healthy volunteers following administration of a single doses of $50 \mu \mathrm{g}(2 \times 25$ $\mu \mathrm{g} /$ actuation $), 150 \mu \mathrm{g}(6 \times 25 \mu \mathrm{g} /$ actuation $)$ and $300 \mu \mathrm{g}(12 \times 25 \mu \mathrm{g} /$ actuation) of the test and reference formulations of salmeterol. The PD study was a single-center, randomized, double-blind, placebo controlled, seven-way, crossover study.

The inclusion criteria for the PK and PD studies were as follows: healthy men aged between 18 and 45 years; Body Mass Index (BMI) between 18 and $25 \mathrm{~kg} / \mathrm{m}^{2}\left(18.5-30 \mathrm{~kg} / \mathrm{m}^{2}\right.$ for PK study with spacer; 18 $26 \mathrm{~kg} / \mathrm{m}^{2}$ for PD study); $\mathrm{FEV}_{1}>80 \%$ of that predicted by the European Community for Coal and Steel (ECCS) formulae (confirmed by spirometry test); no medical history of significant diseases; normal findings as determined by laboratory parameters, physical examination, and vital signs; negative result for breath alcohol test and test for drugs of abuse; and able to perform the inhalation technique correctly.

Subjects were excluded from the PK and PD studies if they had known history of hypersensitivity to salmeterol xinafoate, any component of the product, or related class of drug; had history of chronic bronchitis, emphysema, asthma or any other lung disease of clinical significance; had recent upper or lower respiratory tract infection; had consumed drugs that induce/inhibit the hepatic microsomal enzymes two months prior to dosing; and had ingested any herbal product, prescribed or nonprescribed drug four weeks prior to dosing and throughout the study.

\section{Study products}

In all the PK and PD studies, subjects fasted overnight for at least $10 \mathrm{~h}$. The study inhalers were shaken well and primed before using for the first time. In the PK study with spacer, the spacers were also primed from inside to reduce the static charges.

In the PK studies with and without charcoal, subjects selfadministered single dose of either test or reference product (salmeterol xinafoate HFA $25 \mu \mathrm{g} /$ actuation $\times 8$ puffs) as per the randomization sequence in both the periods, with a gap of at least $30 \mathrm{~s}$ between each puff. Additionally, in the PK study with charcoal, $50 \mathrm{~mL}$ (approximately $5 \mathrm{~g}$ ) activated charcoal suspension was given $2 \mathrm{~min}$ prior to the first puff and $2 \mathrm{~min}$ after last puff, followed by $100 \mathrm{~mL}$ (approximately 10 g) activated charcoal suspension at 1,2 , and $3 \mathrm{~h}$ post dose, according to the methods of Borgstrom and Nilsson and validated for salmeterol by Bennett et al. [22]. In the PK study with spacer, after an overnight fasting of at least $10 \mathrm{~h}$, subjects self-administered a single dose of either test or reference product (salmeterol xinafoate HFA $25 \mu \mathrm{g} /$ actuation $\times 4$ puffs) with the help of a Volumatic spacer. Deep breathing technique was used for inhalation through the spacer device as it has a lesser variability as compared to tidal breathing method [27].

In the PD study, subjects were randomized to receive salmeterol xinafoate HFA and placebo on 7 separate days as follows: test product (2 puffs $=50 \mu \mathrm{g})+$ reference placebo, test product $(6$ puffs $=150 \mu \mathrm{g})+$ reference placebo, test product $(12$ puffs $=300 \mu \mathrm{g})+$ reference placebo, test placebo+reference product $(2$ puffs $=50 \mu \mathrm{g})$, test placebo+reference product $(6$ puffs $=150 \mu \mathrm{g})$, test placebo+reference product $(12$ puffs $=300$ $\mu \mathrm{g})$, and test placebo+reference placebo.

\section{Pharmacokinetic analysis}

In all the three PK studies, the pre-dose samples were taken within 1 $\mathrm{h}$ prior to dosing; and salmeterol plasma levels were analyzed over a $24 \mathrm{~h}$ period. At each time point, $5 \mathrm{~mL}$ of blood sample was collected in a test tube containing an anticoagulant.

For the PK studies, the primary $\mathrm{PK}$ variables were $\mathrm{C}_{\max }$ and $\mathrm{AUC}_{0-\mathrm{t}^{\circ}}$ Analysis of plasma samples for concentrations of salmeterol was done 
Citation: Morde N, Rebello J, Brashier B, Garg M, Naidu R, et al. (2017) Comparison of Pharmacokinetic and Pharmacodynamic Effects of Two Hydrofluoroalkane Formulations of Salmeterol. J Bioequiv Availab 9: 405-411. doi: 10.4172/jbb.1000332

using a validated liquid chromatography-mass spectrometry (LC MS)/ MS method. The Lower Limit of Quantification (LLOQ) of this method for the estimation of salmeterol concentrations in plasma was $5 \mathrm{pg} / \mathrm{mL}$ in the PK studies with and without charcoal and $2 \mathrm{pg} / \mathrm{mL}$ in the PK study with spacer. A non-compartmental method was used to calculate the PK parameters using drug concentrations versus time profile.

\section{Pharmacodynamic analysis}

Approximately $12 \mathrm{~h}$ after dosing, subjects blood sample collection and safety evaluations were carried out. Heart rates were measured by pulse oximeter for the first $9 \mathrm{~min}$ after dosing at an interval of $1 \mathrm{~min}$. Heart rate, QTc interval, blood pressure and venous sampling for assay of serum potassium and plasma glucose was assessed at $10 \mathrm{~min}, 20 \mathrm{~min}$, $30 \mathrm{~min}, 40 \mathrm{~min}, 60 \mathrm{~min}, 90 \mathrm{~min}, 2 \mathrm{~h}, 3 \mathrm{~h}, 4 \mathrm{~h}, 6 \mathrm{~h}, 8 \mathrm{~h}, 10 \mathrm{~h}$, and $12 \mathrm{~h}$ post dose. Tremor assessment was done at $30 \mathrm{~min}$ pre dose and at $30 \mathrm{~min}, 1$, 2,4 , and $6 \mathrm{~h}$ post dose.

The primary endpoints were Maximum Heart Rate (MxHR) over $12 \mathrm{~h}$ and Minimum Serum Potassium level (MnSP) over $4 \mathrm{~h}$ at the lower dose of $50 \mu \mathrm{g}$. The secondary endpoints were MxHR (0-12 h) and MnSP $(0-4 \mathrm{~h})$ at the higher doses $(150 \mu \mathrm{g}$ and $300 \mu \mathrm{g})$; and maximum systolic blood pressure (0-12 h), minimum diastolic blood pressure $(0-12 \mathrm{~h})$, maximum QTc interval ( $0-12 \mathrm{~h})$, and maximum plasma glucose levels (0-12 h) for all doses.

\section{Safety analysis}

For all the four pharmacology studies, safety was evaluated by monitoring of Adverse Events (AEs), Serious Adverse Events (SAEs), physical examination, blood pressure, pulse rate, serum potassium, blood glucose, tremor assessment, well-being assessment, and ECG.

\section{Statistical analysis}

Pharmacokinetic studies: All the PK studies were designed with a sample size of 24 subjects to obtain minimum of 12 evaluable subjects to obtain reasonable data for appropriate comparison.

Analysis of covariance (ANOVA), two one-sided tests for relative bioavailability of test and reference products was compared for $\mathrm{C}_{\max }$, and $\mathrm{AUC}_{0-\mathrm{t}}$ using WinNonlin software version 5.2. Difference in median $\mathrm{T}_{\max }$ was evaluated by non-parametric Mann-Whitney $\mathrm{U}$ or Wilcoxon Rank-Sum two-sample test procedure using NCSS 97 Software. In all PK studies, the bioequivalence limit of $80 \%$ to $125 \%$ was used for both $\mathrm{C}_{\max }$ and $\mathrm{AUC}_{0-\mathrm{t}}$, except in the PK study with charcoal (being the first study), and in which considering the rapid absorption of salmeterol from the lung vascular bed, a slightly wider bioequivalence limit of $75 \%$ to $133 \%$ was proposed for $\mathrm{C}_{\max }$.

Pharmacodynamic study: In the PD study, assuming no difference between the two treatments, 14 subjects were considered sufficient to allow equivalence to be detected if the $95 \%$ Confidence Interval (CI) for the mean difference between the two treatments is within $\pm 10 \mathrm{bpm}$ for heart rate and $\pm 0.33 \mathrm{mmol} / \mathrm{L}$ for serum potassium concentration. Accordingly to account for the dropouts, 21 subjects were enrolled in the study.
The equality or proximity of heart rate and serum potassium level at baseline over periods was analyzed using ANOVA. The treatment difference was calculated from Least Square Mean (LSM), and the $95 \%$ CIs were determined using the estimate option in mixed procedure in SAS Software.

In addition to the above analysis, additional relative potency analysis was also conducted for the primary endpoints in the PD study. The relative dose potency of the two salmeterol HFA formulations was calculated as the horizontal distance between parallel lines approximating the dose-response curves. The statistical analysis of the data included an ANOVA associated with the statistical model containing the factors: sequence, subject nested within sequence, formulation, dose, formulation $\times$ dose interaction, subject (sequence) $\times$ dose interaction as factors in the model. Using the ANOVA model, the linear slope of the log dose-response curve was estimated for both the formulations. 95\% CIs for the relative potency were computed according to Fieller's theorem. Equivalence was to be concluded if the $90 \%$ CI calculated for the log (relative potency) was within $0.67-1.50$ [28].

\section{Results}

\section{Study population}

Table 1 shows the baseline demographics of the study populations. In the PK studies with charcoal and spacer, all 24 subjects were randomized and analyzed for final bioequivalence analysis. In the PK study without charcoal, 24 subjects were randomized, and 20 were analyzed for final bioequivalence analysis (4 subjects were withdrawn due to inadequate inhalation technique). In the PD Study, 21 were randomized, and 16 completed the study and were analyzed for primary PD analysis. In the PD study, 2 subjects dropped out due to personal reason, 2 due to AEs and 1 due to inadequate inhalation technique. The baseline characteristic of the healthy volunteers across the PK and PD studies were similar which thereby enables cross comparison between the studies.

Comparison of systemic exposure between two formulations of salmeterol (upper $90 \%$ CI limit of the difference was $136 \%$; Table 2; Figure 1): The $90 \% \mathrm{CI}$ of the difference for $\mathrm{AUC}_{0-\mathrm{t}}$ was within the bioequivalence limits of $80 \%$ to $125 \%$; however, the $\mathrm{C}_{\max }$ of the test formulation marginally exceeded than that of the reference formulation (upper 90\% CI limit of the difference was 136\%; Table 2; Figure 1). The marginally higher levels in $\mathrm{C}_{\max }$ with the test formulation had no impact on the PD variables such as heart rate, serum potassium, blood glucose, and QTc interval as compared to the reference formulation when evaluated at predefined intervals over $24 \mathrm{~h}$ in the same study.

Comparison of pulmonary deposition between two formulations of salmeterol (PK study with charcoal): The $90 \%$ CI of the difference for $\mathrm{C}_{\max }$ was within the bioequivalence limits of $80 \%$ to $125 \%$; however, $\mathrm{AUC}_{0-\mathrm{t}}$ of the test formulation was marginally exceeded than that of the reference formulation (upper 90\% CI limit of the difference was $128 \%$; Table 2, Figure 2). The difference in AUC observed for the test

\begin{tabular}{|c|c|c|c|c|}
\hline Parameters & $\begin{array}{l}\text { PK Study with charcoal } \\
\qquad(\mathrm{N}=24)\end{array}$ & $\begin{array}{l}\text { PK study without charcoal } \\
\qquad(\mathrm{N}=20)\end{array}$ & $\begin{array}{l}\text { PK study with spacer } \\
\text { ( } \mathrm{N}=24)\end{array}$ & $\begin{array}{l}\text { PD Study } \\
(\mathrm{N}=21)\end{array}$ \\
\hline Age (years) & $26.42 \pm 4.12$ & $25.90 \pm 6.69$ & $25.96 \pm 5.24$ & $26.7 \pm 4.1$ \\
\hline Weight (kg) & $63.37 \pm 8.30$ & $61.92 \pm 7.43$ & $62.15 \pm 6.57$ & $60.81 \pm 6.66$ \\
\hline Height (cm) & $169.39 \pm 7.28$ & $168.53 \pm 6.07$ & $167.75 \pm 5.43$ & $166.8 \pm 5.4$ \\
\hline BMI $\left(\mathrm{kg} / \mathrm{m}^{2}\right)$ & $22.06 \pm 2.28$ & $21.76 \pm 2.22$ & $22.06 \pm 1.76$ & $21.84 \pm 1.95$ \\
\hline
\end{tabular}

Note: All values are in mean \pm SD. 
Citation: Morde N, Rebello J, Brashier B, Garg M, Naidu R, et al. (2017) Comparison of Pharmacokinetic and Pharmacodynamic Effects of Two Hydrofluoroalkane Formulations of Salmeterol. J Bioequiv Availab 9: 405-411. doi: 10.4172/jbb.1000332

\begin{tabular}{|c|c|c|c|c|}
\hline PK Parameters & Test (T) & Reference (R) & $\%(T / R)^{*}$ & $90 \% \mathrm{Cl}$ \\
\hline \multicolumn{5}{|c|}{ PK Study with charcoal $(\mathrm{N}=24)$} \\
\hline $\mathrm{AUC}_{0-\mathrm{t}}(\mathrm{pg} \cdot \mathrm{h} / \mathrm{mL})$ & 1230.16 & 1088.09 & 113.06 & $99.58-128.35$ \\
\hline $\mathrm{C}_{\max }(\mathrm{pg} / \mathrm{mL})$ & 891.01 & 807.07 & 110.40 & $99.33-122.71$ \\
\hline $\mathrm{AUC}_{0-30 \min }(\mathrm{pg} \cdot \mathrm{h} / \mathrm{mL})$ & 223.02 & 199.36 & 111.87 & $(100.99-123.91)$ \\
\hline $\mathrm{T}_{\max }(\mathrm{h})$ & $0.05(0.05-0.08)$ & $0.05(0.05-0.08)$ & - & - \\
\hline \multicolumn{5}{|c|}{ PK study without charcoal $(\mathrm{N}=20)$} \\
\hline$A \cup C_{0-t}(p g \cdot h / m L)$ & 1502.27 & 1453.13 & 103.38 & $92.07-116.09$ \\
\hline $\mathrm{C}_{\max }(\mathrm{pg} / \mathrm{mL})$ & 972.98 & 880.01 & 110.56 & $89.70-136.29$ \\
\hline $\mathrm{AUC}_{0-30 \min }(\mathrm{pg} \cdot \mathrm{h} / \mathrm{mL})$ & 222.18 & 214.61 & 103.53 & $85.13-125.90$ \\
\hline $\mathrm{T}_{\max }(\mathrm{h})$ & $0.05(0.03-0.08)$ & $0.05(0.03-0.08)$ & - & - \\
\hline \multicolumn{5}{|c|}{ PK study with spacer $(\mathrm{N}=24)$} \\
\hline $\mathrm{AUC}_{0-\mathrm{t}}(\mathrm{pg} \cdot \mathrm{h} / \mathrm{mL})$ & 1271.42 & 1402.13 & 90.68 & $83.87-98.03$ \\
\hline $\mathrm{C}_{\max }(\mathrm{pg} / \mathrm{mL})$ & 1391.64 & 1471.96 & 94.54 & $87.11-102.61$ \\
\hline$A \cup C_{0-30 \min }(\mathrm{pg} \cdot \mathrm{h} / \mathrm{mL})$ & 327.76 & 355.84 & 92.11 & $85.50-99.23$ \\
\hline $\mathrm{T}_{\max }(\mathrm{h})$ & $0.05(0.03-0.10)$ & $0.05(0.03-0.12)$ & - & - \\
\hline
\end{tabular}

All values are in geometric mean except $\mathrm{T}_{\max }$ which is in median (range). ${ }^{*}(\%) \mathrm{T} / \mathrm{R}$ is ratio of TestGeoLSM/RefGeoLSM.

Table 2: Pharmacokinetic parameters.

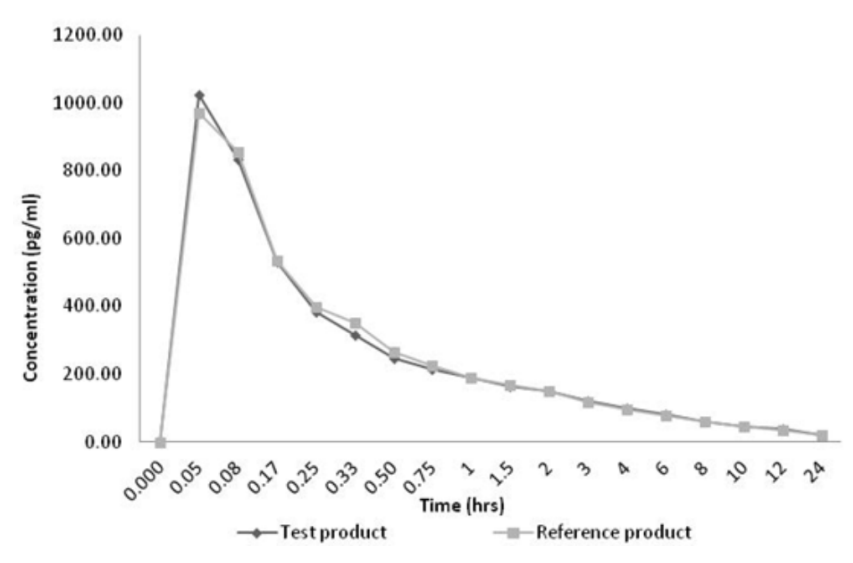

Figure 1: Plasma concentration-time curves in PK study without charcoal.

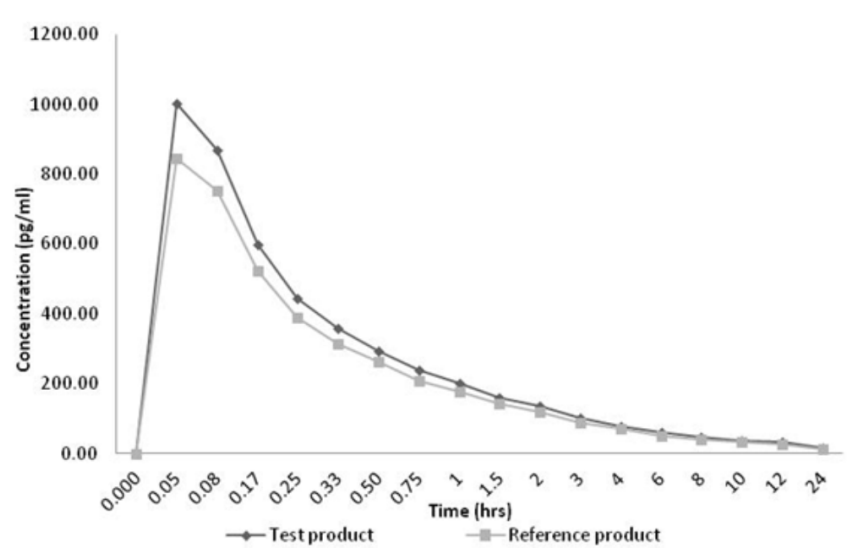

Figure 2: Plasma concentration-time curves in PK study with charcoal.

product is unlikely to result in differential pharmacological effects, since the systemic effects of salmeterol (such as increase in heart rate, serum potassium) is likely to correlate with peak concentrations and early absorption due to rapid appearance of salmeterol in blood. The marginally higher levels in AUC with the test formulation had no impact on the PD variables such as heart rate, serum potassium, blood glucose, and QTc interval as compared to the reference formulation evaluated at predefined intervals over $24 \mathrm{~h}$ in the same study.

Comparability in systemic exposure with spacer device using two formulations of salmeterol: The $90 \%$ CIs of the difference for both $\mathrm{AUC}_{0-\mathrm{t}}$ and $\mathrm{C}_{\max }$ were within the bioequivalence limits of $80 \%$ to $125 \%$ (Table 2 and Figure 3) with the volumatic spacing device. The test formulation showed an increase of around $40 \%$ and the reference formulation showed an increase of around 54\% with the spacer device in peak plasma concentration as compared to the conventional actuator. The increase in lung deposition with the spacer device is consistent with the published studies with Volumatic spacer device $[29,30]$.

Comparison of systemic PD effects of the two formulations of salmeterol: At each of the doses, the $95 \%$ CI for the treatment difference was within the clinically relevant limits of $\pm 10 \mathrm{bpm}$ for increase in heart rate and $\pm 0.33 \mathrm{nmol} / \mathrm{L}$ for decrease in serum potassium (Table 3; Figures 4 and 5). The treatments were also comparable for the other safety variables such as blood glucose and QTc interval.

The relative potency was also calculated for heart rate and serum potassium using $150 \mu \mathrm{g}$ and $300 \mu \mathrm{g}$ doses as these doses were on the steep part of the dose response curve. The $90 \%$ CI for the relative potency was well within limits of $0.67-1.5$ for $\operatorname{MxHR}(0-12 \mathrm{~h})$ and MnSP (0-4 h) (Table 4).

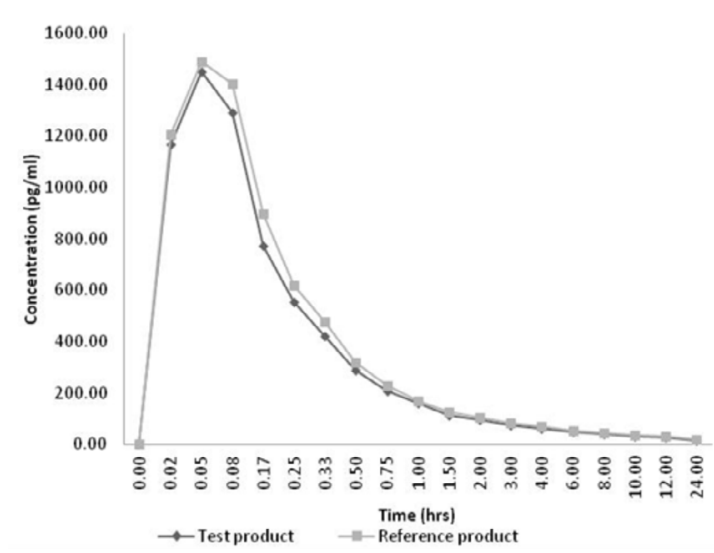

Figure 3: Plasma concentration-time curves in PK study with spacer. 
Citation: Morde N, Rebello J, Brashier B, Garg M, Naidu R, et al. (2017) Comparison of Pharmacokinetic and Pharmacodynamic Effects of Two Hydrofluoroalkane Formulations of Salmeterol. J Bioequiv Availab 9: 405-411. doi: 10.4172/jbb.1000332

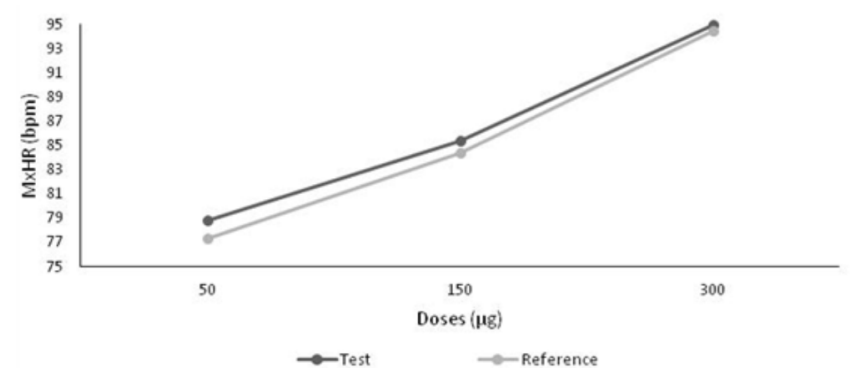

Figure 4: Maximum heart rate $(0-12 \mathrm{~h})$ comparison between test and reference products.

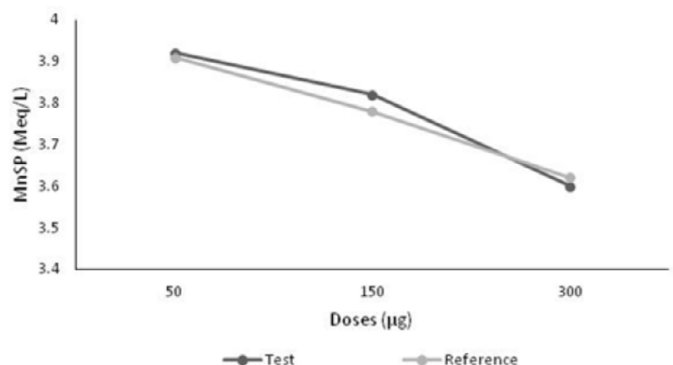

Figure 5: Minimum serum potassium ( $0-4 \mathrm{~h})$ comparison between test and reference products.

\section{Safety}

No AEs were reported in the PK studies with and without charcoal. In the PK study with spacer, 2 subjects experienced mild hand tremors (Table 5). In all the three PK studies, changes in safety parameters such as heart rate, QTc interval, serum potassium, and blood glucose in comparison with baseline were seen with both formulations. However, there were no relevant differences observed between the two formulations in any of the safety parameters, post-study laboratory data, or results of physical examinations in any of the studies. There were no deaths or other SAEs reported in any of the PK studies.

In the PD study, tremor was the most common TreatmentEmergent Adverse Event (TEAE) observed with all the doses of both treatment formulations with maximum occurrence at the highest dose. All TEAEs were mild. Both salmeterol formulations were well tolerated. No SAE was noted throughout the study period.

\section{Discussion}

To our knowledge, this is the first literature evaluating the impact of PK findings on the PD effects when comparing two salmeterol HFA formulations. The PK data presented here were generated using different techniques suitable for OIPs, such as with and without charcoal blockade method and using a spacer device.

The test batch used in the PK studies with and without charcoal and in the PD study was the same which enables cross comparison and evaluation of the impact of $\mathrm{PK}$ findings on the PD effects across studies more appropriately.

Rigorous training on the inhalation technique was provided to the subjects prior to the start of the study with an in-check dial, placebo inhaler, and practice spacer device (where applicable) in all the PK studies. The pulmonary absorption peak observed in all PK studies was within 5 min which indicates that all subjects had performed the inhalation technique correctly. All PK studies had a washout period of 7 days. No pre-dose levels were seen in any of the PK studies, which indicate that the washout period was adequate in all PK studies. The mean $\mathrm{AUC}_{0-\mathrm{t}} / \mathrm{AUC}_{0 \text {-inf }}$ was $>80 \%$ in all $\mathrm{PK}$ studies which indicated that the sampling duration of $24 \mathrm{~h}$ was adequate for complete characterization of salmeterol profile. The LLOQ $(5 \mathrm{pg} / \mathrm{mL})$ used in the PK studies presented in this paper was 5 to 12 times below what has been used in published studies which enabled complete characterization of the PK profile till $24 \mathrm{~h}$ even with $200 \mu \mathrm{g}$ and $100 \mu \mathrm{g}$ doses [20,31].

It is known that pMDIs have no flow rate dependency; therefore, healthy subjects were selected for the PK and PD studies. In addition, healthy cohort is the most sensitive cohort to detect differences arising due to the device/formulation that are not confounded by factors (e.g. airway caliber changes) which can cause PK/PD differences that are independent of differences in the device/formulation.

The salmeterol concentration reported in the PK study without charcoal is consistent to findings in the published literature in healthy subjects. The $\mathrm{C}_{\text {max }}$ obtained was $972 \mathrm{pg} / \mathrm{mL}$ and $880 \mathrm{pg} / \mathrm{mL}$ with $200 \mu \mathrm{g}$ of the test and reference formulations, respectively, which is consistent with $700.8 \mathrm{pg} / \mathrm{mL}$ which was obtained with $150 \mu \mathrm{g}$ of salmeterol. The AUC values reported with $200 \mu \mathrm{g}$ doses of the test and reference formulations are 1502.27 and $1453.13 \mathrm{pg} / \mathrm{mL} . \mathrm{h}$, respectively, which are far greater than $558.9 \mathrm{pg} / \mathrm{mL} . \mathrm{h}$ reported with $150 \mu \mathrm{g}$ of salmeterol as we able to characterize the complete plasma profile of salmeterol at the dose used in the PK studies [20]. As expected, higher AUC levels were observed with spacer for both the formulations.

The differences between salmeterol given with and without charcoal indicate that approximately $25 \%$ of the systemic response to salmeterol administration is due to drug absorbed from the gastrointestinal tract. This is in accordance with the study by Bennett and Tattersfield wherein $28 \%$ to $36 \%$ of salmeterol systemic response was due to drug absorbed from the gastrointestinal tract [22]. The exponential decline, single plasma peaks within 5 min post administration, and lack of additional secondary peaks indicates an effective blockage of gastrointestinal absorption by charcoal. Although the with and without charcoal comparisons have been derived from two separate studies, both the PK studies were conducted under the same standardized set up such as same dose, same centre, same design, similar sampling duration, and similar washout periods; subjects studied in both studies were healthy and had similar demographic profile.

The PK studies demonstrated that the test formulation had a marginally higher plasma concentration compared with the reference formulation. However, it should be noted that no significant difference was seen in systemic $\beta 2$-mediated adverse effects (maximum heart rate and maximal fall in potassium); even at 6 times the recommended single dose in the assay-sensitive PD study. Likewise, the test formulation had no pronounced effects on other $\beta 2$ agonist PD effects such as QTc interval, maximum systolic blood pressure, and maximum plasma glucose concentration. Considering that the systemic exposure of the test product was marginally greater in the PK studies, the PD study was therefore a good alternative clinical study model to evaluate impact of greater systemic exposure and additionally evaluate relative potency by satisfying the requirement of the OIP guideline in terms of assay sensitivity.

Dose-response curves of the systemic drug effects are equally important for establishing full therapeutic equivalence. The ratio of doses giving equivalent effects (potency ratio) indicates relative potency of two formulations [32,33]. In a previous study, three doses of formoterol $(24,48$, and $96 \mu \mathrm{g})$ and salmeterol $(100,200$ and $400 \mu \mathrm{g})$ 
Citation: Morde N, Rebello J, Brashier B, Garg M, Naidu R, et al. (2017) Comparison of Pharmacokinetic and Pharmacodynamic Effects of Two Hydrofluoroalkane Formulations of Salmeterol. J Bioequiv Availab 9: 405-411. doi: 10.4172/jbb.1000332

\begin{tabular}{|c|c|c|c|c|c|}
\hline \multirow{2}{*}{ Parameter } & \multirow{2}{*}{ Dose } & \multicolumn{2}{|c|}{ Least Square Means } & \multirow{2}{*}{ Difference } & \multirow{2}{*}{$95 \%$ Confidence Interval } \\
\hline & & Test & Reference & & \\
\hline MxHR (beats/min) & $50 \mu \mathrm{g}$ & 78.79 & 77.31 & 1.47 & $(-2.8711,5.8155)$ \\
\hline MnSP (Meq/L) & $50 \mu g$ & 3.92 & 3.91 & 0.02 & $(-0.1350,0.1678)$ \\
\hline \multirow{2}{*}{ MxHR (beats/min) } & $150 \mu \mathrm{g}$ & 85.40 & 84.39 & 1.01 & $(-3.3289,5.3577)$ \\
\hline & $300 \mu \mathrm{g}$ & 94.91 & 94.44 & 0.47 & $(-3.8694,4.8173)$ \\
\hline \multirow{2}{*}{ MnSP (Meq/L) } & $150 \mu \mathrm{g}$ & 3.82 & 3.78 & 0.04 & $(-0.1101,0.1927)$ \\
\hline & $300 \mu \mathrm{g}$ & 3.60 & 3.62 & -0.01 & $(-0.1648,0.1380)$ \\
\hline
\end{tabular}

MxHR: Maximum Heart Rate; MnSP: Minimum Serum Potassium.

Table 3: Maximum heart rate (0-12 h) and minimum serum potassium $(0-4 \mathrm{~h})$.

\begin{tabular}{|c|c|c|}
\hline Parameter & Relative Potency & 90\% Confidence Interval \\
\hline Maximum Heart rate $0-12 \mathrm{~h}$ & 1.05 & $0.88-1.27$ \\
\hline Minimum serum potassium 0-4 h & 0.98 & $0.67-1.41$ \\
\hline
\end{tabular}

Table 4: Relative potency analysis for heart rate between doses $150 \mu \mathrm{g}$ and 300 $\mu \mathrm{g}$ (PP population).

\begin{tabular}{|c|c|c|c|}
\hline Adverse Event & Test & Reference & Placebo \\
\hline Tremor & 14 & 15 & 3 \\
\hline Headache & 2 & 2 & 1 \\
\hline High blood pressure & $3^{*}$ & 1 & 0 \\
\hline Throat pain & 1 & 0 & 0 \\
\hline
\end{tabular}

*Event was report twice in one subject.

Table 5: Drug-related adverse events (PD study).

were evaluated to estimate relative potency between the two drugs [33]. Relative potency was adequately estimated in this study as both drugs had dose-related effects on the systemic parameters. The relative dose potency for systemic effect such as maximum heart rate was $4.1(95 \%$ CI: 3.0 to 5.6 ) over $4 \mathrm{~h}$. This indicates that formoterol is 4.1 times more potent than salmeterol. It is interesting to note that the 4 -fold difference in the recommended doses of formoterol and salmeterol $(12 \mu \mathrm{g}$ formoterol vs. $50 \mu \mathrm{g}$ salmeterol twice daily) are similar in their relative dose potency ratio of 1:4 for systemic endpoints. Therefore, in absence of a sensitive efficacy clinical model relative potency of a product can be adequately evaluated through a PD safety model.

The PD model utilized in the PD safety study presented in this paper is a well-established model used by Bennett and Tatters field and subsequently elaborated by Guhan et al. [33] and satisfies the requirement of assay sensitivity. Therefore the $\mathrm{PD}$ study reconfirms that the test product was equipotent to the reference product.

The data presented in this paper raise some interesting points with respect to the procedure for establishing therapeutic equivalence between generic and innovator products. A product may be acceptable to patients and clinicians if there is no clinical difference between the two formulations, even if bioequivalence is not established. Therefore it is important to evaluate difference in PK data in conjunction with PD data to understand the relevance of its impact on the efficacy and safety.

\section{Conclusion}

Overall, it can be concluded that the test HFA formulation of salmeterol is therapeutically equivalent to the reference HFA formulation of salmeterol when used with and without the spacer device. Both test and reference products were safe and well tolerated.

\section{Acknowledgement}

Each author contributed in literature search, data collection, study design, analysis of data, manuscript preparation, and review of manuscript. This publication was supported by Sitec Labs., India; and Cipla Ltd., India was the sponsor of these studies.

\section{Conflict of Interest}

The authors have indicated that they have no other conflicts of interest regarding the content of the article.

\section{References}

1. World Health Organization (2013) Asthma.

2. World Health Organization (2013) Burden of COPD.

3. American Lung Association (2012) Trends in Asthma Morbidity and Mortality.

4. European Respiratory Society (2003) European Lung White Book: Huddersfield. Eur Respir Soc J.

5. Global Initiative for Chronic Obstructive Lung Disease (2016) Global Strategy for the Diagnosis, Management, and Prevention of Chronic Obstructive Pulmonary Disease.

6. Global Initiative for Asthma (GINA) (2015) Global Strategy for Asthma Management and Prevention.

7. Calverley PM, Anderson JA, Celli B, Ferguson GT, Jenkins C, et al. (2007) Salmeterol and fluticasone propionate and survival in chronic obstructive pulmonary disease. N Engl J Med 356: 775-789.

8. Boyd G, Morice AH, Pounsford JC, Siebert M, Peslis N, et al. (1997) An evaluation of salmeterol in the treatment of chronic obstructive pulmonary disease (COPD). Eur Respir J 10: 815-821.

9. Cazzola M, Matera MG, Santangelo G, Vinciguerra A, Rossi F, et al. (1995) Salmeterol and formoterol in partially reversible severe chronic obstructive pulmonary disease: a dose-response study. Respir Med 89: 357-362.

10. Rossi A, Kristufek P, Levine BE, Thomson MH, Till D, et al. (2002) Comparison of the efficacy, tolerability, and safety of formoterol dry powder and oral, slowrelease theophylline in the treatment of COPD. Chest 121: 1058-1069.

11. Ulrik CS (1995) Efficacy of inhaled salmeterol in the management of smokers with chronic obstructive pulmonary disease: a single centre randomised, double blind, placebo controlled, crossover study. Thorax 50: 750-754.

12. Tashkin DP, Fabbri LM (2010) Long-acting beta-agonists in the management of chronic obstructive pulmonary disease: current and future agents. Respir Res 11: 149.

13. Al-Numania D, Colucci P, Ducharme MP (2015) Rethinking bioequivalence and equivalence requirements of orally inhaled drug products. Asian J Pharmaceut Sci 10: 461-471.

14. Sandstrom T, Frederiksen B, Rosenhall L, Sandstrom B (1989) Salmeterol - a dose response study with a long-acting inhaled beta2-agonist. Am Rev Respir Dis 139: A64.

15. GSK Study SLGH05 (2005) GSK data.

16. Rabe KF, Jörres R, Nowak D, Behr N, Magnussen H (1993) Comparison of the effects of salmeterol and formoterol on airway tone and responsiveness over 24 hours in bronchial asthma. Am Rev Respir Dis 147: 1436-1441.

17. Palmqvist M, Persson G, Lazer L, Rosenborg J, Larsson P, et al. (1997) Inhaled dry-powder formoterol and salmeterol in asthmatic patients: onset of action, duration of effect and potency. Eur Respir J 10: 2484-2489.

18. O'Connor D, Adams WP, Chen ML, Daley-Yates P, Davis J, et al. (2011) Role of pharmacokinetics in establishing bioequivalence for orally inhaled drug products: workshop summary report. J Aerosol Med Pulm Drug Deliv 24:119-135. 
Citation: Morde N, Rebello J, Brashier B, Garg M, Naidu R, et al. (2017) Comparison of Pharmacokinetic and Pharmacodynamic Effects of Two Hydrofluoroalkane Formulations of Salmeterol. J Bioequiv Availab 9: 405-411. doi: 10.4172/jbb.1000332

19. Goyal N, Hochhaus G (2010) Demonstrating Bioequivalence using pharmacokinetics: theoretical considerations across drug classes. Respir Drug Del 1: 261-272.

20. Kempsford R, Handel M, Mehta R, De Silva M, Daley-Yates P (2005) Comparison of the systemic pharmacodynamic effects and pharmacokinetics of salmeterol delivered by CFC propellant and non-CFC propellant metered dose inhalers in healthy subjects. Respir Med 99: S11-S19.

21. Cazzola M, Testi R, Matera MG (2002) Clinical pharmacokinetics of salmeterol. Clin Pharmacokinet 41: 19-30.

22. Bennett JA, Harrison TW, Tattersfield AE (1999) The contribution of the swallowed fraction of an inhaled dose of salmeterol to it systemic effects. Eur Respir J 13: 445-448.

23. Committee for Human Medicinal Products (2015) Questions \& Answers: positions on specific questions addressed to the Pharmacokinetics Working Party (PKWP). European Medicines Agency, London E14 5EU, UK.

24. World Medical Assoiciation (2008) WMA declaration of Helsinki-ethical principles for medical research involving human subjects. WMA General Assembly, Seoul, Korea.

25. ICH Expert Working Group (1996) ICH Harmonized Tripartite Guideline for Good Clinical Practice.

26. European Medicines Agency (2009) Guideline on the requirements for clinical documentation for Orally Inhaled Products (OIP) including the requirements for demonstration of therapeutic equivalence between two inhaled products for use in the treatment of asthma and Chronic Obstructive Pulmonary Disease (COPD) in adults and for treatment of asthma in children and adolescents.

27. Roller CM, Zhang G, Troedson RG, Leach CL, Le Souëf PN, et al. (2007) Spacer inhalation technique and deposition of extrafine aerosol in asthmatic children. Eur Respir J 29: 299-306.

28. Pritchard JN (2001) The influence of lung deposition on clinical response. J Aerosol Med 14: S19-S26.

29. Lipworth BJ, Clark DJ (1998) Lung delivery of non-CFC salbutamol via small volume metal spacer and large volume plastic spacer devices compared with an open vent jet nebulizer. Br J Clin Pharmacol 45: 160-163.

30. Lipworth BJ, Clark DJ (1998) Early lung absorption profile of non-CFC salbutamol via small and large volume plastic spacer device. $\mathrm{Br} \mathrm{J}$ Clin Pharmacol 46: 45-48.

31. Kirby S, Falcoz C, Daniel MJ, Milleri S, Squassante L, et al. (2001) Salmetero and fluticasone propionate given as a combination. Lack of systemic pharmacodynamic and pharmacokinetic interactions. Eur J Clin Pharmacol 56 781-791.

32. Bennett JA, Tattersfield AE (1997) Time course and relative dose potency of systemic effects from salmeterol and salbutamol in healthy subjects. Thorax 52: 458-464.

33. Guhan AR, Cooper S, Oborne J, Lewis S, Bennett J, et al. (2000) Systemic effects of formoterol and salmeterol: a dose-response comparison in healthy subjects. Thorax 55: 650-656. 